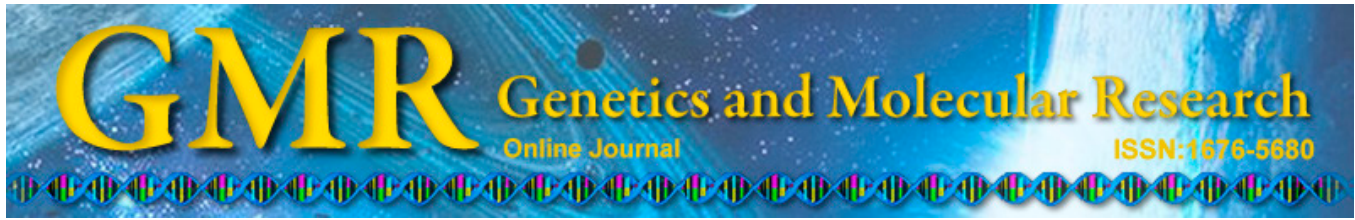

\title{
MicroRNA-21 promotes proliferation of rat hepatocyte BRL-3A by targeting FASLG
}

\author{
J.J. Li ${ }^{1,2}$, W.H. Chan ${ }^{3}$, W.Y. Leung ${ }^{3}$, Y. Wang ${ }^{3}$ and C.S. Xu ${ }^{1,2}$ \\ ${ }^{1}$ State Key Laboratory Cultivation Base for Cell Differentiation Regulation, \\ Henan Normal University, Xinxiang, China \\ ${ }^{2}$ College of Life Science, Henan Normal University, Xinxiang, \\ Henan Province, China \\ ${ }^{3}$ College of Life Science and Technology, Jinan University, Guangzhou, \\ Guangdong Province, China
}

Corresponding author: C.S. Xu

E-mail: cellkeylab@126.com

Genet. Mol. Res. 14 (2): 4150-4160 (2015)

Received May 21, 2014

Accepted October 30, 2014

Published April 27, 2015

DOI http://dx.doi.org/10.4238/2015.April.27.30

\begin{abstract}
Rat liver regeneration (RLR) induced by partial hepatectomy involves cell proliferation regulated by numerous factors, including microRNAs (miRNAs). miRNA high-throughput sequencing has been established and used to analyze miRNA expression profiles. This study showed that 39 miRNAs were related to RLR through the analysis of miRNA high-throughput sequencing. Their role toward rat normal hepatocyte line BRL-3A was studied by gain- and lossof-function analyses, and one of them, microRNA-21 (miR-21), obviously upregulated and promoted BRL-3A cell proliferation. Using bioinformatics to search for miR-21 targets revealed that Fas ligand (FASLG) is one of miR-21's target genes. A dual-luciferase report assay and Western blot assay showed that miR-21 directly targeted the 3'-untranslated region of FASLG and inhibited the expression of FASLG, which suggests that miR-21 promoted BRL-3A cell proliferation by reducing FASLG expression.
\end{abstract}

Key words: Apoptosis; Cell proliferation; FAS ligand (FASLG); Liver regeneration; MicroRNA-21 (miR-21) 


\section{INTRODUCTION}

The liver has an enormous capacity for regeneration (Fausto et al., 1995; Sell, 2003). When injured or undergoing a partial hepatectomy $(\mathrm{PH})$, hepatocytes are rapidly activated, proliferate, and restore the lost liver tissues; these processes are called liver regeneration (LR) (Taub, 2004; Xu et al., 2004). In recent years, an increasing number of studies have shown that microRNAs (miRNAs) such as miR-127, miR-34a, and miR-23b, play an important role in liver growth, development, and regeneration (Chen et al., 2011; Yuan et al., 2011; Pan et al., 2012).

miRNAs are a class of endogenous, small regulatory RNA molecules with a length of about 25 nucleotides (nt), and are found mostly in introns and intergenic regions. miRNAs are generally derived from a 70-nt RNA precursor and directed to their target mRNAs by binding to the 3'-UTR of their target mRNAs. This inhibits translation or induces mRNA degradation. In vivo, one miRNA can bind to a plurality of target mRNAs, and in turn, one target gene can be regulated by multiple miRNAs, which is called the "multiple target" hypothesis (Bonci et al., 2008; Creighton et al., 2012). This suggests that dysregulated miRNAs could regulate a number of biological processes through the miRNA-regulatory network (Mavrakis et al., 2011; Ooi et al., 2011).

In the present study, miRNA high-throughput sequencing was used to identify differentially expressed miRNAs related to LR. Through gain-of-function and loss-of-function studies, it was shown that miR-21 promoted BRL-3A cell growth and proliferation. In addition, using TargetScan, miRANDA, GO, KEGG, and the NCBI websites to predict miR-21 targets, we found that the apoptosis protein FAS ligand (FASLG) was one of miR-21's target genes. Dual-luciferase report assays and Western blotting showed that miR-21 directly targeted the 3'-UTR of FASLG and inhibited FASLG's expression. These results indicated that miR-21 promoted BRL-3A cell proliferation by targeting FASLG.

\section{MATERIAL AND METHODS}

\section{Preparation of rat liver regeneration model}

Adult Sprague-Dawley rats, weighing $230 \pm 20$ g, were provided by the Animal Center of Henan Normal University. The rats were kept at $21^{\circ} \pm 2{ }^{\circ} \mathrm{C}$ with a relative humidity of 60 $\pm 10 \%$, illumination of a 12 -h period (8:00-20:00), and free access to water and food. A total of 114 rats were randomly divided into 19 groups of six animals: nine PH groups, nine SO (sham operation) groups, and one control group. The rats in the $\mathrm{PH}$ groups were subjected to $2 / 3$ partial hepatectomy in accordance with the methods of Higgins and Anderson (1931). Briefly, the left and median lateral liver lobes, constituting about $70 \%$ of the liver weight, were surgically removed. The rats in the SO groups underwent the same operative process without removal of the liver lobes. After surgery, the abdominal cavity was reopened to collect liver tissue at 2, $6,12,24,30,36,72,120$, and $168 \mathrm{~h}$ post-surgically. The tissues were stored at $-80^{\circ} \mathrm{C}$ in RNA Later (kit purchased from Ambion Inc., USA). All experiments were carried out in accordance with the current Animal Protection Law of China.

\section{miRNA high-throughput sequencing}

Liver tissues were harvested and pooled for RNA extraction using a mirVana miRNA Isolation Kit (Ambion) according to manufacturer instructions. The quality of the total 
RNA was detected by agarose gel electrophoresis ( $110 \mathrm{~V}, 0.5 \mathrm{~h})$, mass, concentration, and purity of miRNA was measured at 260 and $280 \mathrm{~nm}$ wavelengths. The samples with a ratio of $\mathrm{OD}_{260 / 280}$ of approximately 2.0 were used. Qualitative and quantitative analysis of miRNAs was conducted by the Shanghai Biotechnology Corporation. The read length of single-ended Solexa microRNA-Seq sequencing is $36 \mathrm{nt}$. By comparing a sequence with the miRNA library, the type and abundance of different miRNAs were determined.

\section{Identification of miRNAs associated with liver regeneration}

In this study, miRNAs with expressive abundance $\geq 20$ were used. Of them, the miRNAs with ratio values of $\mathrm{PH} \geq 2$ or $\leq 0.5$, showed significant changes. $t$-testing was used to analyze the differences in the expression of miRNAs between the PH and SO groups. The miRNAs, which were significantly changed $(0.01 \leq \mathrm{P}<0.05)$ or highly significantly changed $(\mathrm{P}<0.01)$ at least one time point during $\mathrm{LR}$ were defined as LR-associated miRNAs.

\section{Quantitative real-time PCR (qRT-PCR) assay}

To validate the reliability of microarray data, the expression level of miRNA related to LR was examined by qRT-PCR. Total RNA was isolated from liver tissues using a mirVana miRNA Isolation Kit (Ambion) and cDNA was synthesized using the AMV reverse transcription kit (Promega, USA). The primer sequences (including specific Stem-Loop reverse transcription (RT) primers and qRT-PCR primers) were designed using the Primer Express software, version 5.0. The primers and U6 (a kind of small nuclear RNA) were synthesized by Shanghai Sangon Biological Engineering Company. The qRT-PCR was performed using Q-SYBR green Supermix (BioRad), and PCR-specific amplification was conducted in Rotor-Gene 3000 (Corbett Robotics, Australia). The expression of miRNA was defined based on the threshold cycle (Ct), and relative expression levels were calculated via the $2^{-\Delta \Delta \mathrm{Ct}}$ method. U6 small nuclear RNA served as an internal reference. All experiments were performed at least three times.

\section{Normal rat hepatocyte BRL-3A (BRL-3A cells) culturing}

Normal rat hepatocyte BRL-3A (BRL-3A cells) were purchased from the Institute of Biochemistry and Cell Biology (Shanghai, China). The cells were cultured with DMEM (GIBCO) containing 10\% fetal bovine serum (HyClone) and 1\% penicillin and streptomycin in a humidified atmosphere of $5 \% \mathrm{CO}_{2}$ at $37^{\circ} \mathrm{C}$. When cells were in their logarithmic growth phase, each bottle was inoculated with a $5-\mathrm{mL}$ cell suspension at a concentration of $5 \times 10^{4}$ cells $/ \mathrm{mL}$.

\section{MTT assay}

An MTT assay was used to detect the growth viability of BRL-3A cells in vitro. Briefly, $5 \times 10^{3}$ BRL-3A cells were seeded into each well of 96-well plates and transfected with mimic/inhibitor negative control (NC mimics/inhibitors): $50 \mathrm{nM} \mathrm{miR} \mathrm{mimics} \mathrm{or} 100$ $\mathrm{nM}$ miR inhibitors at their respective final concentrations. At the post-transfect 24, 48, and $72 \mathrm{~h}$ time points, $100 \mu \mathrm{L}$ spent medium was replaced with an equal volume of fresh medium containing MTT (Sigma) $0.5 \mathrm{mg} / \mathrm{mL}$. The plates were incubated at $37^{\circ} \mathrm{C}$ for $4 \mathrm{~h}$, after which the medium was replaced by $100 \mu \mathrm{L}$ DMSO (Sigma). Plates were shaken at room temperature for $10 \mathrm{~min}$. The absorbance was measured at $490 \mathrm{~nm}$. 


\section{BrdU labeling assay}

A BrdU labeling assay was used to measure the proliferation rate of BRL-3A cells. Briefly, $6 \times 10^{4}$ BRL-3A cells were seeded into each well of 6-well plates and transfected with $\mathrm{NC}$ mimics/inhibitors, miR mimics or miR inhibitors at a final concentration of 50 or $100 \mathrm{nM}$ for the mimics and inhibitors, respectively. After $48 \mathrm{~h}, 1 \mathrm{~mL}$ medium with BrdU replaced the former medium, and was stained for $2 \mathrm{~h}$ at $37^{\circ} \mathrm{C}$. The cells were then washed in PBS and fixed in $70 \%$ alcohol for $60 \mathrm{~min}$ at $4^{\circ} \mathrm{C}$. Next, the cells were treated in $0.1 \%$ tyrisin at $37^{\circ} \mathrm{C}$ for 1 $\mathrm{h}$ and denatured in $1 \mathrm{M} \mathrm{HCl}$ at $56^{\circ} \mathrm{C}$ for $15 \mathrm{~min}$, and incubated with anti-BrdU monoclonal antibody (Sigma, USA) at $37^{\circ} \mathrm{C}$ for $40 \mathrm{~min}$ and FITC-secondary antibody (Sigma) for $35 \mathrm{~min}$ at room temperature. The cell nuclei were stained with 4',6-diamidino-2-phenylindole (DAPI; Sigma). The cells were washed in PBS 3 times after each step described above, and 10 random non-overlapping fields were selected using a fluorescence microscope. The number of BrdUlabeled cells and nuclei in the same fields were counted by the Image-Pro Plus 6.0 software. The ratio of proliferating cells was are reported as the proportion of BrdU-labeled cells compared to the total number of cells. The data are reported as means $\pm \mathrm{SD}$.

\section{Cell cycle analysis by flow cytometry}

Flow cytometry was used to test whether miRNA influenced the cell cycle of BRL-3A. In brief, $1 \times 10^{6} \mathrm{BRL}-3 \mathrm{~A}$ cells were seeded into each well of 6-well plates and transfected with NC mimics/inhibitors, miRNA mimics or miRNA inhibitors at a final concentration of $50 \mathrm{nM}$ (mimics) or $100 \mathrm{nM}$ (inhibitors), respectively. The cells were harvested and washed in PBS at post-transfect 24 and $48 \mathrm{~h}$ time points, then fixed in $70 \%$ alcohol for 60 min at $4{ }^{\circ} \mathrm{C}$. After washing in cold PBS 3 times, cells were resuspended and incubated in $1 \mathrm{~mL}$ PBS solution with $50 \mu \mathrm{g}$ propidium iodide (PI; Sigma) and $100 \mu \mathrm{g}$ RNase A (Sigma) for $30 \mathrm{~min}$ at $37^{\circ} \mathrm{C}$. Samples were then analyzed for their DNA content by FACSCan.

\section{Prediction of miRNA target genes}

TargetScan (http://www.targetscan.org/), miRanda (http://www.microrna.org/), miRDB (http://mirdb.org/miRDB/), and miRWalk (http://www.umm.uni-heidelberg.de/apps/ $\mathrm{zmf} /$ mirwalk/index.html) were used to predict the potential target genes of the miRNAs. To ensure the target genes accuracy, target genes co-predicted by at least three of the four datasets were used for subsequent functional analysis. In addition, we used go ontology (GO; http://www.geneontology. org/) and the Kyoto Encyclopedia of Genes and Genomes pathway (KEGG; http://www.genome. jp/kegg/pathway.html) to conduct the target gene annotation and pathway analysis .

\section{Dual luciferase reporter assay}

Luciferase reporters were constructed by cloning target mRNA 3'-UTR sequences into the psiCHECK-2 vector (Promega). The 3'-UTR of wild-type FASLG containing the FASLGmiR-21 response element, as well as the mutant 3'-UTR of FASLG, were synthesized by Shanghai Generay Biotech Co., Ltd. Cells were co-transfected with the reporter plasmid (0.5 $\mu \mathrm{g})$ and miRNA mimics, inhibitors, and control using Lipofectamine 2000 (Invitrogen). Re- 
porter assays were performed using the Dual Luciferase Reporter Assay System (Promega) following the manufacturer protocol after the transfect $48 \mathrm{~h}$ timepoint. The data were normalized for transfection efficiency by dividing Firefly luciferase activity with that of Renilla luciferase.

\section{Western blot analysis}

BRL-3A cells were lysed on ice with RIPA buffer (50 mM Tris, $150 \mathrm{mM} \mathrm{NaCl}, 1 \%$ Triton $100 \mathrm{X}, 1 \%$ sodium deoxycholate, $0.1 \%$ SDS $)$ containing proteinase inhibitors $(1 \mathrm{mM}$ phenylmethylsulfonyl fluoride, $2 \mu \mathrm{g} / \mathrm{mL}$ aprotinin, and $2 \mu \mathrm{g} / \mathrm{mL}$ leupeptin). Protein concentration was quantified using the Neuhoff Assay (Neuhoff et al., 1979). Ten milligram of protein per sample was boiled in $5 \mathrm{X}$ SDS sample buffer for $5 \mathrm{~min}$, separated by SDS-polyacrylamide gel electrophoresis and transferred to nitrocellulose membranes (GE Healthcare, USA). After the transfer, the membranes were blocked with 5\% skimmed milk in Tris-buffered saline (TBS) containing $0.1 \%$ Tween-20 (TBS-T) and subsequently incubated with target protein or $\beta$-actin primary antibodies overnight at $4^{\circ} \mathrm{C}$. After washing with TBS-T for $30 \mathrm{~min}$ at room temperature, the membrane was further incubated with horseradish peroxidase-conjugated secondary antibodies for $1.5 \mathrm{~h}$, followed by 30 min of washing with TBS-T. Protein bands were visualized with Amersham ECL substrates.

\section{Statistical analysis}

Statistical significance was estimated using the Student $t$-test. A P value less than 0.05 was considered to be significant. In addition, all the experiments described in the figures were repeated at least three times. All values are reported as means \pm SD.

\section{RESULTS}

\section{Rat liver regeneration-related miRNAs}

In this study, 425 miRNAs were detected in regenerating rat livers at 2, 6, 12, 24, 30, $36,72,120$, and $168 \mathrm{~h}$ after PH by high-throughput Solexa sequencing. Of them, the expression abundance of 126 miRNAs was greater than 20. Compared with the control group (PH-0 h), 31 miRNAs in the PH groups were 2-fold upregulated and 4 miRNAs 2-fold downregulated at least one time point. $t$-tests showed that 23 miRNAs were related to liver regeneration (Table 1). To further validate the miRNA high-throughput sequencing results, qRT-PCR was used to detect these miRNAs. The results showed that 4 miRNAs, including miR-21, miR-191, miR-141, and miR-429, had a similar expression trend between qRT-PCR and highthroughput array results, and they were used for further functional study (Figure 1).

\section{miR-21 promotes BRL-3A cell proliferation in vitro}

The 4 kinds of miRNAs mentioned above were selected for functional analysis in vitro. miRNA mimics and inhibitors were used for performing gain-of-function or loss-offunction studies. The growth ability of BRL-3A cells was detected using an MTT assay. The result showed that among these 4 miRNAs, miR-21 could change cell growth ability after 24 , 48 , and $72 \mathrm{~h}$ by mimic and inhibitor treatments (Figure 2A). 


\begin{tabular}{|c|c|c|c|c|c|c|c|c|c|c|}
\hline \multirow[t]{2}{*}{ MicroRNAs } & \multicolumn{9}{|c|}{ Recovery time (h) after partial hepatectomy } & \multirow[t]{2}{*}{$t$-test } \\
\hline & $2 \mathrm{~h}$ & $6 \mathrm{~h}$ & $12 \mathrm{~h}$ & $24 \mathrm{~h}$ & $30 \mathrm{~h}$ & $36 \mathrm{~h}$ & $72 \mathrm{~h}$ & $120 \mathrm{~h}$ & $168 \mathrm{~h}$ & \\
\hline let-7a-1 & 0.9095 & 1.1581 & 0.9300 & 0.6927 & 0.6842 & 0.6213 & 0.6113 & 0.6246 & 0.4584 & 0.0066 \\
\hline $\operatorname{mir}-100$ & 2.2324 & 1.0074 & 0.9514 & 1.1732 & 0.5062 & 0.8437 & 0.4849 & 0.8808 & 0.7242 & 0.2389 \\
\hline $\operatorname{mir}-106 b$ & 0.9116 & 0.8002 & 1.6117 & 1.4003 & 1.7977 & 1.8600 & 2.1762 & 1.7671 & 1.7356 & 0.0156 \\
\hline $\operatorname{mir}-10 b$ & 2.9416 & 0.8380 & 0.7667 & 1.5313 & 0.8755 & 0.8700 & 0.3932 & 0.3328 & 0.6163 & 0.0951 \\
\hline $\operatorname{mir}-125 a$ & 2.3634 & 1.6799 & 1.2236 & 1.0875 & 0.5393 & 1.5769 & 0.8039 & 1.3606 & 1.0254 & 0.0003 \\
\hline mir-127 & 6.9102 & 0.4722 & 0.3158 & 0.9478 & 0.1982 & 0.4670 & 0.6853 & 0.3567 & 0.9127 & 0.2695 \\
\hline mir-141 & 10.2337 & 1.2602 & 1.2262 & 1.8991 & 1.5167 & 2.1534 & 0.8354 & 0.8059 & 1.8855 & 0.1090 \\
\hline mir-142 & 0.9444 & 0.9368 & 1.2467 & 1.0458 & & 1.3139 & 1.5951 & 1.8053 & 1.3295 & 0.0155 \\
\hline mir-143 & 2.0272 & 0.8770 & 0.8750 & 1.2797 & 0.8468 & 0.9105 & 0.6994 & 0.9057 & 0.8351 & 0.2141 \\
\hline mir-145 & 2.8113 & 1.6354 & 1.1905 & 1.0276 & 1.0895 & 0.7550 & 0.7038 & 0.6705 & 0.5358 & 0.2615 \\
\hline $\operatorname{mir}-145^{*}$ & 2.7767 & 1.0408 & 1.4195 & 1.0794 & 0.6346 & 1.5033 & 0.5907 & 0.8337 & 0.6610 & 0.0738 \\
\hline mir-148b & 1.1531 & 1.2204 & 1.2709 & 1.1829 & 2.0907 & 1.6408 & 1.7534 & 2.4059 & 1.3989 & 0.0008 \\
\hline $\operatorname{mir}-150$ & 1.5961 & 2.0530 & 1.5369 & 1.3827 & 1.1696 & 1.1998 & 0.7771 & 0.8705 & 0.6977 & 0.0222 \\
\hline mir- $15 b$ & 1.1045 & 1.1227 & 1.1814 & 1.3953 & 2.1489 & 2.7658 & 3.1060 & 2.5707 & 2.0280 & 0.4054 \\
\hline mir-16 & 1.1152 & 1.0786 & 1.1806 & 1.0807 & 2.1301 & 1.5181 & 1.7424 & 1.0454 & 1.2832 & 0.0113 \\
\hline mir-181c & 2.6088 & 0.9163 & 1.0537 & 1.1510 & 0.9400 & 0.9119 & 0.6226 & 0.5911 & 0.5853 & 0.2668 \\
\hline mir-181d & 2.3486 & 0.9565 & 0.9566 & 0.9297 & 0.7561 & 0.8673 & 0.4442 & 0.5687 & 0.7950 & 0.0149 \\
\hline mir-182 & $4.4602^{-}$ & 3.4135 & 2.7876 & 1.2937 & 1.6261 & 1.5573 & 1.4096 & 1.6384 & 1.9012 & 0.0006 \\
\hline mir-183 & 4.7491 & 3.1133 & 2.9119 & 1.4400 & 2.1934 & 1.9902 & 2.2083 & 1.9625 & & 0.0061 \\
\hline mir-191 & 1.1742 & 1.2629 & 1.4578 & 1.4514 & 1.9286 & 2.2820 & 1.8377 & 1.6836 & 1.4276 & 0.0011 \\
\hline mir-199a & 2.8531 & 1.3277 & 1.2650 & 1.4822 & 1.3328 & 0.9751 & 0.9226 & 1.3627 & 1.3192 & 0.0107 \\
\hline mir-200a & 1.5551 & 1.4373 & 1.1707 & 1.3072 & 1.7912 & 1.6067 & 1.2317 & 0.6995 & 0.8830 & 0.1583 \\
\hline mir-200b & 4.1515 & 2.0194 & 2.3717 & 1.4193 & 1.2637 & 1.5272 & 2.0792 & 1.1143 & 1.3914 & 0.0210 \\
\hline mir-203 & 0.4557 & 0.7932 & 0.9952 & 0.7707 & 1.4474 & 0.7989 & 0.7331 & 0.6634 & 0.6157 & 0.3392 \\
\hline mir-21 & 1.1141 & 1.4846 & 1.7601 & 1.6071 & & 1.7182 & & 1.8626 & 1.9188 & 0.0032 \\
\hline $\operatorname{mir}-21 *$ & 1.2335 & 2.4107 & 4.2554 & 2.7968 & 5.6546 & 2.9179 & 2.4634 & 2.5779 & 1.9688 & 0.0021 \\
\hline mir-214 & 2.0545 & 1.4006 & 1.0063 & 1.2617 & 1.1864 & 1.0779 & 0.8107 & 1.4072 & 1.3154 & 0.1861 \\
\hline $\operatorname{mir}-221$ & 2.5003 & 1.2008 & 1.6622 & 1.3933 & 1.7259 & 1.6280 & 472 & 1.7091 & 1.3244 & 0.0007 \\
\hline $\operatorname{mir}-223$ & 0.9224 & 0.7084 & 1.4032 & 1.4816 & 1.5539 & 0.8338 & 1352 & 1.2211 & 0.8366 & 0.0252 \\
\hline mir-34a & 0.6509 & 0.8443 & 1.1072 & 1.2406 & 2.9691 & 1.8378 & 3.9148 & 2.7216 & 3.5981 & 0.3130 \\
\hline $\operatorname{mir}-375$ & 0.7574 & 0.8334 & 1.1600 & 0.8738 & 0.6063 & 0.8830 & 0.8481 & 0.3413 & 0.5260 & 0.1369 \\
\hline $\operatorname{mir}-423^{*}$ & 1.7460 & 2.5315 & 2.1572 & 1.2645 & 0.8911 & & 0.9745 & 1.9748 & 1.3088 & 0.1027 \\
\hline $\operatorname{mir}-425$ & 1.1673 & 1.2032 & 1.3774 & 1.6033 & 2.0566 & 2.3080 & 1.9207 & 1.2250 & 1.6072 & 0.0008 \\
\hline $\operatorname{mir}-429$ & & 1.8478 & 2.1290 & 1.2979 & 0.8934 & 1.6514 & 1.4987 & 1.0980 & 1.1760 & 0.3864 \\
\hline $\operatorname{mir}-582 *$ & 1.1342 & 0.9575 & 1.2059 & 1.4464 & 1.0447 & 0.9192 & 1.2642 & 2.0506 & 1.6599 & 0.0676 \\
\hline mir-802 & 0.4855 & 0.9703 & 1.0204 & 0.9893 & 0.8499 & 1.1935 & 1.0358 & 1.0238 & 0.8495 & 0.2668 \\
\hline mir-92a- $1 *$ & 1.0126 & 1.8962 & 2.0085 & 1.8682 & 1.2648 & 1.4797 & 1.5106 & 0.6266 & 0.6943 & 0.0011 \\
\hline mir-96 & .5574 & 2.5623 & 2.8626 & 1.2089 & 1.8898 & 1.8769 & 2.0492 & 1.9101 & 1.6284 & 0.1338 \\
\hline mir-99b & 2.1542 & 1.2454 & 1.1087 & 1.0772 & 1.1648 & 1.2001 & 1.0479 & 1.6248 & 1.2897 & 0.0252 \\
\hline
\end{tabular}
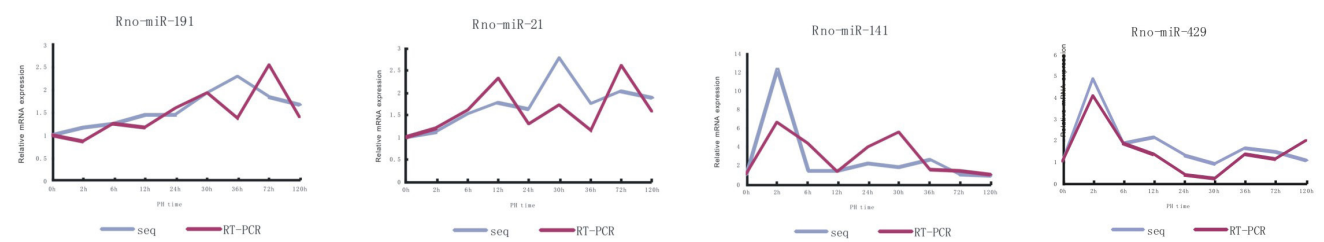

Figure 1. miRNA expression in the regenerating rat liver tissue after partial hepatectomy. The miRNA expression levels were examined by miRNA high-throughput sequencing (blue lines) and qRT-PCR analysis (purple lines) at the indicated time points after partial hepatectomy $(\mathrm{PH})$. Data are reported as means $\pm \mathrm{SD}$ of at least three independent experiments and are reported as the $2^{-\Delta \Delta C t}$ ratio between miRNAs and U6, which was used for normalization of expression. The value of the $\mathrm{PH}-0 \mathrm{~h}$ sample was calculated as 1 .

Next, a BrdU-labeling assay was used to evaluate the cell proliferation rate. The results showed that the percentage of labeled cells in the miR-21 mimic-treated group was high- 
er than in the NC group. Meanwhile the inhibitor-treated group presented the opposite pattern (Figure 2B and C).

To further confirm the role of miR-21 on cell proliferation, we performed cell cycle analysis by flow cytometry. The results indicated that the proportion of cells in the S- and G2/M-phase after being, respectively, transfected with miR-21 mimic or miR-21 inhibitor was enhanced and diminished, compared with NC (Figure 2D).
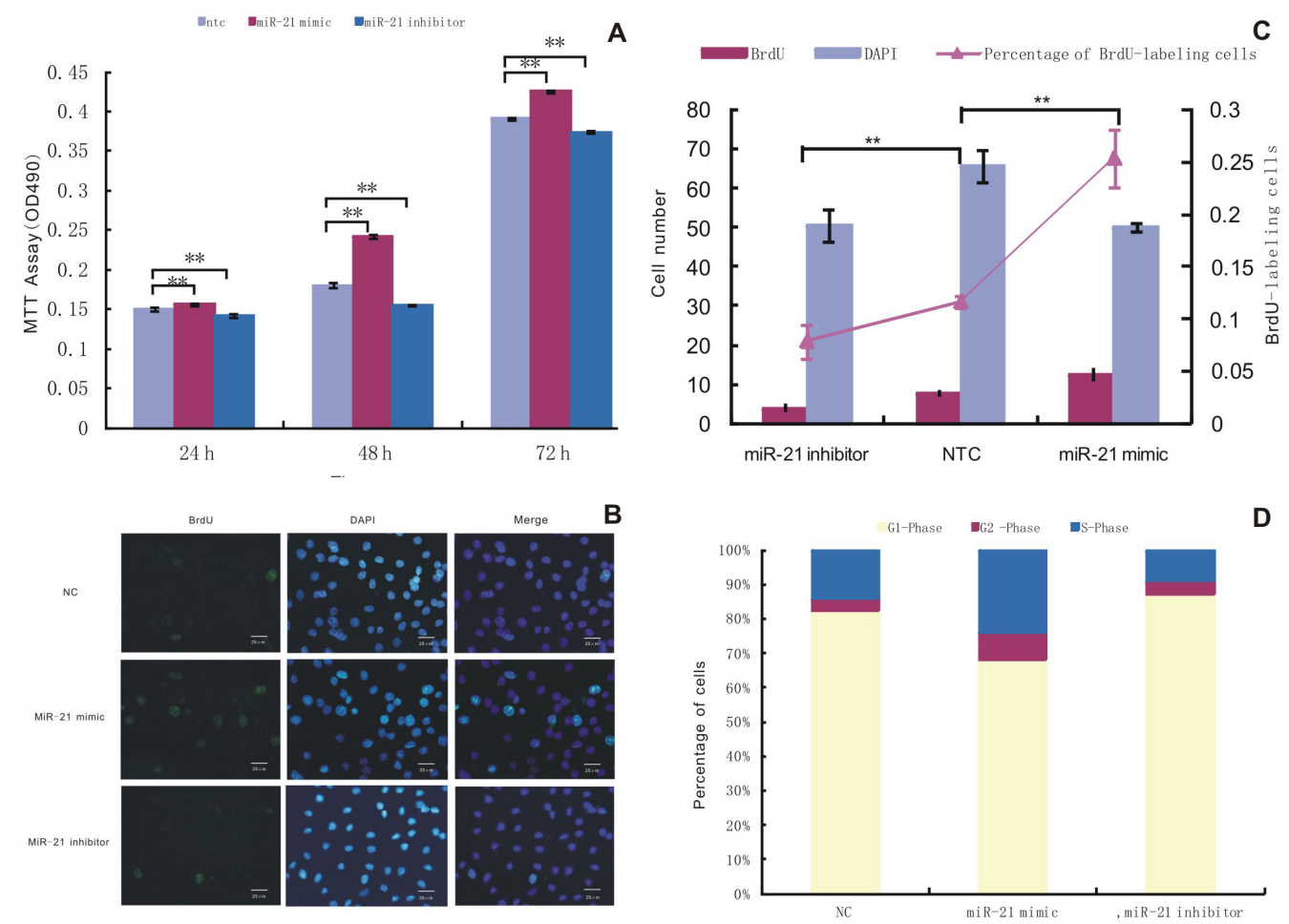

Figure 2. Functional analysis of miR-21 in vitro. BRL-3A cells were treated with negative control (NC), 50 $\mathrm{nM}$ miR-21 mimic, and $100 \mathrm{nM}$ miR21 inhibitor, respectively. A. MTT assay evaluating cell growth rate in the indicated time points after transfection $(* * \mathrm{P}<0.01)$. B. BrdU and DAPI double-stained cells show the proliferative cells. Original magnification: 400X. Scale bar: $25 \mu \mathrm{m}$. C. BrdU-labeling assay result. Percentage of BrdU-labeling cells after transfection with miR-21 mimic or inhibitor was larger and smaller than the NC group, respectively $(* * \mathrm{P}<0.01)$. Data are reported as means $\pm \mathrm{SD}$ of at least three independent experiments. D. Cell cycle analysis by flow cytometry. Compared with NC, the proportion of cells in the S- and G2/M-phases after being, respectively transfected with miR-21 mimic and miR-21 inhibitor was enhanced (S+G2/M: $31.95 \pm 1.53 \%$ vs $17.81 \pm 1.09 \%$, P $<0.01)$ and diminished (S+G2/M: $12.72 \pm 9.14 \%$ vs $17.81 \pm 1.09 \%, \mathrm{P}<0.01)$. Data are reported as means $\pm \mathrm{SD}$ of at least three independent experiments.

\section{Mechanism of miR-21 promoting BRL-3A cell growth and proliferation}

GO annotations showed that miR-21 target genes participated in the regulation of cell proliferation, differentiation, apoptosis, and protein metabolism (Table 2). Gene interaction network analysis using KEGG found that target genes CCL3, CCL20, IKBKB, STAT3, STAT5A, $N T F 3, F A S L G$, and NR4A1 had higher occurrence rates, and they were taken as the target 
genes for further study. A dual-luciferase reporter assay was used to examine the functional interaction between miR-21 and the putative target sites of predicted target genes.

Table 2. Enrichment analysis of predicted miR-21 targets in KEGG pathway.

\begin{tabular}{ll}
\hline Functions from gene ontologies & P value \\
\hline Modification-dependent protein catabolic process & 0.0006115 \\
Response to wounding & 0.0020552 \\
Positive regulation of cellular biosynthetic process & 0.0045244 \\
Positive regulation of biosynthetic process & 0.0051724 \\
Regulation of myeloid cell differentiation & 0.0106177 \\
Anti-apoptosis & 0.016192 \\
Regulation of apoptosis & 0.0367038 \\
Regulation of programmed cell death & 0.0394175 \\
Regulation of cell death & 0.0403519 \\
Eye development & 0.067538 \\
Regulation of cell proliferation & 0.076426 \\
Positive regulation of cell differentiation & 0.0886922 \\
Sensory organ development & 0.0828861 \\
Positive regulation of myeloid cell differentiation & 0.001624 \\
Protein catabolic process & 0.0017039 \\
Regulation of protein transport & 0.0301926 \\
Regulation of establishment of protein localization & 0.0341378 \\
Proteolysis & 0.073865 \\
\hline
\end{tabular}

The expression of the luciferase reporter containing 3'-UTR of FASLG was found to be inhibited by co-transfection with an miR-21 mimic, but enhanced by co-transfection with an miR-21 inhibitor. In addition, luciferase reporters containing the 3'-UTR mutant site of FASLG had no significantly different expression under transfection with either a mimic or inhibitor (Figure 3A). These results signified FASLG's regulation by miR-21, and had a positive binding site in position 422-429 of its 3'-UTR (Figure 3B). We further measured the expression of FASLG at protein levels by Western blot. The results showed that FASLG expression was suppressed when miR-21 was overexpressed, but enhanced when inhibiting the endogenous miR-21 at protein levels (Figure 3C).
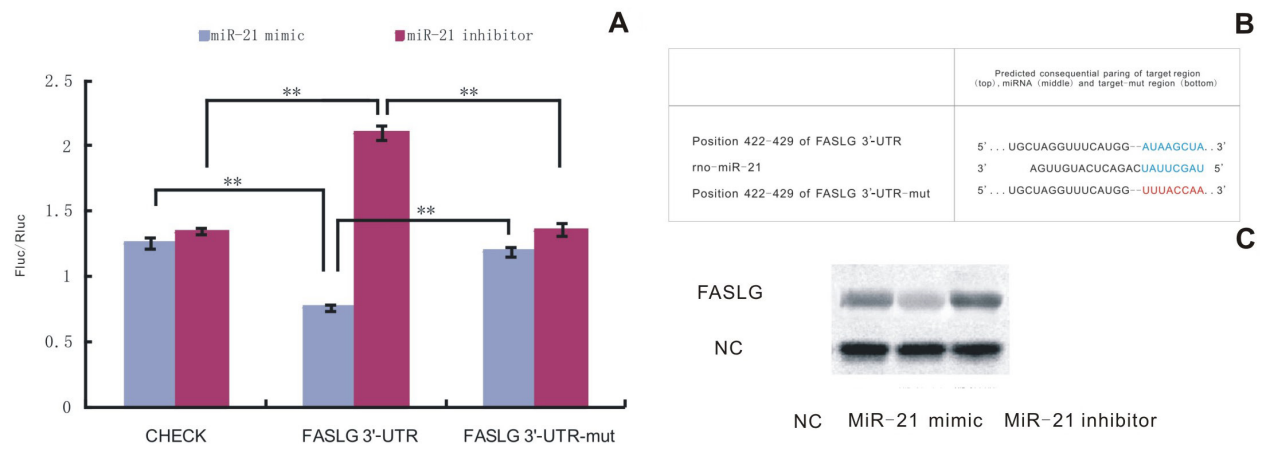

Figure 3. miR-21 targets FASLG to reduce FASLG expression. A. Dual-luciferase reporter containing either the FASLG-3'-UTR or the FASLG-3'-UTR-mut were transfected, respectively, with NC and miR-21 mimic and inhibitor into BRL-3A cells. Renilla luciferase activity was normalized to firefly luciferase. Data are reported as means \pm $\mathrm{SD}$ of at least three independent experiments $(* * \mathrm{P}<0.01)$. B. Schematic of the FASLG 3'-UTR with sequence alignments of miR-21 target binding site. The binding site is shown in blue, and the mutant (mut) site is shown in red. C. Western blotting result showing that the expression of FASLG was suppressed when overexpressing miR21 , but enhanced when inhibiting the endogenous miR-21. 


\section{DISCUSSION}

The $\mathrm{PH}$ rat model is common for studying the mechanisms of liver regeneration. The liver regeneration process is generally divided into three stages: initiation (2-6 h after PH), progression (6-72 h after $\mathrm{PH}$ ), and termination (72-168 h after $\mathrm{PH})$, and involves multiple physiological activities including cell proliferation, differentiation, and apoptosis, which is regulated by various factors such as miRNAs. To understand the mechanism of miRNA regulation of liver regeneration, we examined miRNA expression changes in ratial liver regeneration using high-throughput sequencing. It was found that miR-21 was upregulated during liver regeneration. Previous studies have shown that miRNAs play a regulatory role in liver development and regeneration, and in liver diseases (Katsuda and Ochiya, 2012). The downregulation of miR-127 during rat liver regeneration promotes hepatocyte proliferation (Pan et al., 2012). In addition, the abnormal expression of miR-21 can cause a variety of diseases including hepatocellular carcinoma (HCC; Chan et al., 2005; Iorio et al., 2005; Fulci et al., 2007; Lee et al., 2007; Meng et al., 2007; Huang et al., 2008; Ladeiro et al., 2008). Further studies showed that miR-21 was closely related to liver regeneration in mice (Chaveles et al., 2012). In our study, high-throughput sequencing results found that miR-21 was significantly upregulated, which was also confirmed by qRT-PCR. The $t$-test results showed that miR-21 was closely related to liver regeneration in rats.

Studies showed that miR-21 is found in a variety of organisms, and regulates the expression of multiple target genes including FASLG. The combination of FASLG with Fas death receptor could induce the polymerization of Fas to form death-inducing signaling complex (DISC) by recruiting the death domain adapter protein FADD and Caspase- 8 zymogen (Lee et al., 2006). Caspase- 8 zymogen is activated through autoproteolytic cleavage and subsequently cuts the proapoptotic molecule Bid into an active molecule, tBid (truncated Bid). tBid enters mitochondria and then results in cytochrome $\mathrm{C}$ release from the mitochondria. After a series of cascade reactions, apoptosis is ultimately triggered (Kaufmann and Hengartner, 2001; Cho and Choi, 2002). On the other hand, the binding of FASLG with Fas activates mitogen-activated protein kinase kinase kinase 5 (ASK1) via death domain-associated protein Daxx (Swindall and Bellis, 2011). The activated ASK1 itself activates promitogen activated protein kinase kinase MEKK3/6, MKK4/7, and JNK by a phosphorylation cascade. The activated JNK promotes the release of cytochrome $\mathrm{C}$ and the formation of an apoptosome, thus leading to apoptosis (Li et al., 2013; Arshad et al., 2013). Moreover, dual-luciferase report and Western blot assays showed that miR-21 obviously reduced the expression of FASLG. These results indicated that miR-21 promoted BRL-3A cell proliferation by inhibiting the expression of FASLG.

miR-21 inhibited the neuronal necrosis of rat microglial cells by downregulating FASLG (Zhang et al., 2012). Moreover, in hepatocellular carcinoma, the target gene of miR21 is PTEN (Meng et al., 2007). Meanwhile, miR-21 targets the ubiquitin protein ligase gene Pellino (Peli1; Marquez et al., 2010), suggesting that miR-21 targets different genes in different species, even in different organs. In this paper, mimics and inhibitors of miR-21 were used to transfect BRL-3A cells. We observed that the proliferation of BRL-3A cells was promoted by the mimics of miR-21 and inhibited by the inhibitors of miR-21. Dual-luciferase report assay results showed that miR-21 directly bound to the 3'-UTR of FASLG (Figure 3A and B). Furthermore, Western blot assaying demonstrated that miR-21 inhibited the expression of FASLG. These results suggest that miR-21 reduced FASLG expression to promote hepatocyte proliferation during rat liver regeneration. 


\section{ACKNOWLEDGMENTS}

Research supported by the National Basic Research "973" Pre-Research Program of China (\#2012CB722304), and the Natural Science Foundation of Henan (\#122300413207; \#111100910600; \#132300413208; \#132300410134).

\section{REFERENCES}

Arshad M, Ye Z, Gu X, Wong CK, et al. (2013). RNF13, a RING finger protein, mediates endoplasmic reticulum stressinduced apoptosis through the inositol-requiring enzyme (IRE1 $\alpha$ )/c-Jun NH2-terminal kinase pathway. J. Biol. Chem. 288: 8726-8736.

Bonci D, Coppola V, Musumeci M, Addario A, et al. (2008). The miR-15a-miR-16-1 cluster controls prostate cancer by targeting multiple oncogenic activities. Nat. Med. 14: 1271-1277.

Chan JA, Krichevsky AM and Kosik KS (2005). MicroRNA-21 is an antiapoptotic factor in human glioblastoma cells. Cancer Res. 65: 6029-6033.

Chaveles I, Zaravinos A, Habeos IG, Karavias DD, et al. (2012). MicroRNA profiling in murine liver after partial hepatectomy. Int. J. Mol. Med. 29: 747-755.

Chen H, Sun Y, Dong R, Yang S, et al. (2011). Mir-34a is upregulated during liver regeneration in rats and is associated with the suppression of hepatocyte proliferation. PLoS One 6: e20238.

Cho SG and Choi EJ (2002). Apoptotic Signaling Pathways: Caspases and Stress-Activated Protein Kinases. J. Biochem. Mol. Biol. 35: 24-27.

Creighton CJ, Hernandez-Herrera A, Jacobsen A, Levine DA, et al. (2012). Integrated analyses of microRNAs demonstrate their widespread influence on gene expression in high-grade serous ovarian carcinoma. PLoS One 7: e34546.

Fausto N, Laird AD and Webber EM (1995). Role of growth factors and cytokines in hepatic regeneration. FASEB J. 9: $1527-1536$.

Fulci V, Chiaretti S, Goldoni M, Azzalin G, et al. (2007). Quantitative technologies establish a novel microRNA profile of chronic lymphocytic leukemia. Blood 109: 4944-4951.

Higgins GM and Anderson RM (1931). Experimental pathology of the liver: Restoration of the liver of the white rat following partial surgical removal. Arch. Pathol. 12: 186-202.

Huang YS, Dai Y, Yu XF, Bao SY, et al. (2008). Microarray analysis of microRNA expression in hepatocellular carcinoma and non-tumorous tissues without viral hepatitis. J. Gastroenterol. Hepatol. 23: 87-94.

Iorio MV, Ferracin M, Liu CG, Veronese A, et al. (2005). MicroRNA gene expression deregulation in human breast cancer. Cancer Res. 65: 7065-7070.

Katsuda T and Ochiya T (2012). microRNAs act as a fine-tuner of liver development, regeneration, and carcinogenesis. Seikaqaku 84: 666-674.

Kaufmann SH and Hengartner MO (2001). Programmed cell death: alive and well in the new millennium. Trends Cell Biol. 11: 526-534.

Ladeiro Y, Couchy G, Balabaud C, Bioulac-Sage P, et al. (2008). MicroRNA profiling in hepatocellular tumors is associated with clinical features and oncogene/tumor suppressor gene mutations. Hepatology 47: 1955-1963.

Lee EJ, Gusev Y, Jiang J, Nuovo GJ, et al. (2007). Expression profiling identifies microRNA signature in pancreatic cancer. Int. J. Cancer 120: 1046-1054.

Lee KH, Feig C, Tchikov V, Schickel R, et al. (2006). The role of receptor internalization in CD95 signaling. EMBO J. 25: 1009-1023.

Li LL, Ginet V, Liu X, Vergun O, et al. (2013). The nNOS-p38MAPK pathway is mediated by NOS1AP during neuronal death. J. Neurosci. 33: 8185-8201.

Marquez RT, Wendlandt E, Galle CS, Keck K, et al. (2010). MicroRNA-21 is upregulated during the proliferative phase of liver regeneration, targets Pellino-1, and inhibits NF-kappaB signaling. Am. J. Physiol. Gastrointest. Liver Physiol. 298: G535-541.

Mavrakis KJ, Van Der Meulen J, Wolfe AL, Liu X, et al. (2011). A cooperative microRNA-tumor suppressor gene network in acute T-cell lymphoblastic leukemia (T-ALL). Nat. Genet. 43: 673-678.

Meng F, Henson R, Wehbe-Janek H, Ghoshal K, et al. (2007). MicroRNA-21 regulates expression of the PTEN tumor suppressor gene in human hepatocellular cancer. Gastroenterology 133: 647-658.

Neuhoff V, Philipp K, Zimmer HK and Mesecke S (1979). A simple, versatile, sensitive and volume-independent method for quantitative protein determination which is independent of other external influences. Physiol. Chem. 360: 1657-1660. 
Ooi CH, Oh HK, Wang HZ, Tan AL, et al. (2011). A densely interconnected genome-wide network of microRNAs and oncogenic pathways revealed using gene expression signatures. PLoS Genet. 7: e1002415.

Pan C, Chen H, Wang L, Yang S, et al. (2012). Down-regulation of MiR-127 facilitates hepatocyte proliferation during rat liver regeneration. PLoS One 7: e39151.

Sell S (2003). The hepatocyte: heterogeneity and plasticity of liver cells. Int. J. Biochem. Cell Biol. 35: 267-271.

Swindall AF and Bellis SL (2011). Sialylation of the Fas death receptor by ST6Gal-I provides protection against Fasmediated apoptosis in colon carcinoma cells. J. Biol. Chem. 286: 22982-22990.

Taub R (2004). Liver regeneration: from myth to mechanism. Nat. Rev. Mol. Cell Biol. 5: 836-847.

Xu C, Chang C, Yuan J, Han H, et al. (2004). Identification and characterization of 177 unreported genes associated with liver regeneration. Genom. Proteomics Bioinformatics 2: 109-118.

Yuan B, Dong R, Shi D, Zhou Y, et al. (2011). Down-regulation of miR-23b may contribute to activation of the TGF- $\beta 1 /$ Smad3 signalling pathway during the termination stage of liver regeneration. FEBS Lett. 585: 927-934.

Zhang L, Dong LY, Li YJ, Hong Z, et al. (2012). miR-21 represses FasL in microglia and protects against microgliamediated neuronal cell death following hypoxia/ischemia. Glia 60: 1888-1895. 